\title{
Designing of Infographic via android operating system application for royal graduation ceremony of Ramkhamhaeng University
}

\author{
Tichaporn Namwong ${ }^{1, *}$ and Yotravee Waythongkhum ${ }^{1}$ \\ ${ }^{1}$ Ramkhamhaeng University, Huamak, Bangkapi, Bangkok, Thailand
}

\begin{abstract}
The purpose of this research and development project are; to design and assess quality infographics via an Android Operating System (OS) application for the royal graduation ceremony of Ramkhamhaeng University. The research results found that; (1) The infographics for the royal graduation ceremony of Ramkhamhaeng University were offered on the application RUGrad Version 1.0 on Android OS and included these following items on its menu (1.1) Procedures for the graduation ceremony, (1.2) Graduation registration, (1.3) Attendance report, (1.4) Rehearsals, (1.5) Royal graduation ceremony day, (1.6) Graduates' attires, (1.7) Practices for monks, (1.8) Prohibitions for graduates, (1.9) Diagram for the graduation ceremony process, and (1.10) How to use the application. (2) The quality of infographics shown via the Android OS application was found to be suitable in all areas with the overall value of 0.90 . (3) Graduates of Ramkhamhaeng University participating the 2019 royal graduation ceremony were found with an overall high level of understanding of the ceremony information presented with infographics via the Android OS application $(\overline{\mathrm{x}}=4.49)$. They were also found with an overall high level of satisfaction towards the infographics for the royal graduation ceremony presented via the Android OS application $(\overline{\mathrm{x}}=4.44)$.
\end{abstract}

\section{Introduction}

The present-day Thailand has entered the age of technology and communication which have evolved and changed greatly in various fields in previous years. Access and connection to information in various forms both domestically and internationally have become faster and more convenient. People can communicate with each other using their access to portable and light-weight devices that they carry everywhere such as mobile phones, tablets, etc.

These communications and exchanges of news or information can be done on applications run on various operating systems such as Android OS - a popular operating system developed for mobile devices by Google Inc. using Java programming language and based on a modified version of the Linux kernel. Such easy and convenient access to information obviously becomes a factor influencing cognition, communication, and living

*Corresponding author: tichaporn@hotmail.com 
processes of new-generation people as seen in the growing number of people who use mobile phones and tablets in communication and searching for information. Infographics are another type of media used for providing information, communication, and knowledge which are widely used in various fields including education, business, sports, healthcare, etc.

Infographics are designed by combining processed, analyzed, and summarized data with graphics - either still or animated - designed systematically to create content or information that is easier to perceive and understand. All these are consistent with [1] the statement that infographics are "information transformed into graphics" to be easier to understand and to communicate with people using physical information. As reading through long articles, graphs, or a large-sized information takes time and they might not appeal at all to some people due to the difference in individual interpretation, the use of graphics provides general people better connection between different parts of information.

Infographics are also an outlet for new forms of information presentation making them a delightful form of media [2]. The definition of an information graphic or infographic is a representative of information, data, or knowledge that is explained via the use of graphics which are designed using lines, boxes, arrows, or other symbols. Good infographic designs must be informative and representative of facts. Infographics should also be able to promote perception and understanding of information through its presentation at a good level. [3] The early infographic design only had the concept of a simple data set. Since then, modern information graphic design has been influenced by interdisciplinary theories such as psychology, statistics, sociology, etc., and has continuously improved the ability of visual expression, and the artistic expression of visual elements is valued.

Ramkhamhaeng University has been established as a public higher-education institution since 1971 and held its first royal graduation ceremony on 26th November 1975 for Ramkhamhaeng University 1st graduates [4]. Ramkhamhaeng University had held 43 royal graduation ceremonies and would hold the 44th royal graduation ceremony in 2019 . However, some graduates in the previous years were found lacking knowledge and understanding about the royal graduation ceremony such as inappropriate male and female graduates' attires and hairstyles, rules of conduct during the ceremony, the process of the ceremony, etc.

Even with the university's publication of a graduate handbook and arrangement for unofficial and official rehearsals of the ceremony, such problems did not seem to decrease. Therefore, this study aimed to gather all relevant information, then redesign and create it into animated infographics on an Android OS mobile application in order to publicize and disseminate information about Ramkhamhaeng University's royal graduation ceremony and promote understanding of various practices in the ceremony among students, faculty staff, and those who are interested.

\section{Methodology}

\subsection{Population and sample group}

The sample population consisted of 4 groups; (1) Advisors - 3 of Ramkhamheang University's lecturers were included in the study using purposive sampling to be interviewed regarding the royal graduation ceremonies in academic year 2016-2017. (2) Experts -5 experts were selected using purposive sampling from individuals with expertise in content and infographic designing on Android OS to assess the quality of the infographics used on the Android OS application. (3) 40 fourth year undergraduate students of Ramkhamhaeng university were selected using purposive sampling to test the 
infographics on the Android OS application - 10 students at the first trial and 30 students at the second trial. (4) 300 graduates of Ramkhamhaeng University participating the 2019 royal graduation ceremony were selected using purposively sampling.

The research instruments used were: (1) an advisors' interview form, (2) infographics for the royal graduation ceremony of Ramkhamhaeng University on the Android OS application, (3) an experts' quality assessment form, and (4) a graduates' royal graduation ceremony understanding assessment form and a students' satisfaction evaluation form.

\subsection{Data analysis}

The results of interviews with advisors were analyzed using interpretative conclusion. The results of the experts' assessment on the quality of infographics about Ramkhamhaeng University's royal graduation ceremony were analyzed to find the Item Objective Congruence (IOC) Index. The graduates' understanding assessment form was analyzed to find its IOC Index, while its reliability and discrimination property were indicated by finding the Cronbach's coefficient alpha. The results of graduates' understanding on Ramkhamhaeng University's royal graduation ceremony and their satisfaction on the usage of infographics via the Android OS application were analyzed using descriptive statistics such as Percentage, Mean, and Standard Deviation.

\section{Results and discussions}

The results and discussions of the study "Designing of Infographic via Android Operating System Application for Royal Graduation Ceremony of Ramkhamhaeng University" are as follows:

3.1. Infographics for Ramkhamhaeng University's royal graduation ceremony were offered on the application RUGrad Version 1.0 on Android OS which could be downloaded via Google Play Store and included these following items on its menu

(1) Procedures for the graduation ceremony,

(2) Graduation registration,

(3) Attendance report,

(4) Rehearsals,

(5) Royal graduation ceremony day,

(6) Graduates' attires,

(7) Practices for monks,

(8) Prohibitions for graduates,

(9) Diagram for the graduation ceremony process, and

(10) How to use the application.

The quality of infographics on the Android OS application was found to be suitable in all areas with the overall value of 0.90 . This might be due to the designing of these infographics being done by the research team based on the "9 Steps for Designing and Creating Infographics" of [5] which includes:

(1) Topic selection - the topics selected included all student-related processes and practices for Ramkhamhaeng University's royal graduation ceremony.

(2) Planning - guidelines and procedures were set from the pre-designing, designing, and to post-designing processes. This helped to provide a big picture of working processes, ensuring systematic working and effective designing processes, as well as making them more time-efficient.

(3) Creating a mind map - this helped to connect relevant matters to the working issues in organized taxonomical steps and to provide a clear picture of related pieces of information. 
(4) Searching for various information from reliable sources based on information on the mind map.

(5) Getting inspired by seeking knowledge and new experiences in addition to existing experiences to help guide work processes and to be applied to the designs.

(6) Converting information to graphics - a process which included analysis and screening of the data to be presented. Text data were converted to images or symbols to promote correct understanding and communication with the target audience.

This process is also consistent with [6] who stated that there are two main elements of infographics -

1) information (text) - an important element for the infographic even if they are focused on presenting information with graphics, as it cannot be only pictures. Without informative text, they are not infographics.

2) graphics - an indispensable element in infographics as purely textual presentation of information cannot be referred to as infographics. The graphics used can be in various forms such as geometric shapes, icons, cartoons, charts or diagrams, photographs, etc.

(7) Skating drafts by drawing roughly and quickly and sketching it out in different ways to see the different compositions.

(8) Designing infographics with layouts using design theories such as composition arrangement, colour theory, and font style to create design work with quality and effectiveness.

(9) Checking and improving the accuracy of the work through design discussion and evaluation to gain new perspectives and ideas which in this project was done through assessment of experts with specialty in content and infographic designing on Android OS. The use of infographics on the Android OS application was also tested twice before the results of assessments would be used to improve the infographics, making them accurate, easy to understand, beautiful, and effective in their communication the target audience as shown in Figure 1.
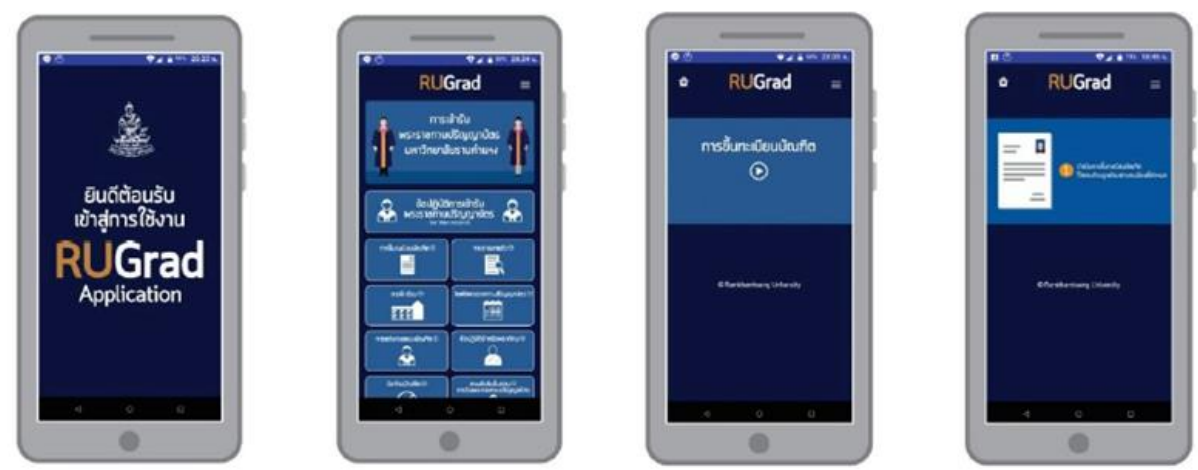

Fig. 1. Welcome page, main menu, video menu for graduate registration.

3.2 Graduates participating in Ramkhamhaeng University's 2019 royal graduation ceremony were found to understand the ceremony information as presented on the Android OS application at a high level $((\overline{\mathrm{x}}=4.49)$ as shown in Table 1 , especially in dress codes for graduates at the royal graduation ceremony according to the university announcement, royal graduation ceremony day, prohibitions for graduates, and the diagram for the graduation ceremony process.

This might be due to the infographics on the Android OS application being motion infographics in video or other animated formats to draw attention to the narrative or explain mechanisms to be easier to understand by using an attractive presentation style. They were 
also easy-to-understand graphics in terms of font style, font size, font color, symbols, background, and layout. All graphics were edited to include audio both narrative audio with correct pronunciation and sound effects or music to supplement the content.

The application's straightforward use might also be another influential factor. This is consistent with [7] which stated that motion infographics or infographics with animated graphics - either in video or other animated formats - are often used in narrative or explanations of mechanisms as they can attract a lot of attention and they are easy to understand. However, their disadvantages include a requirement of higher production costs than still infographics, unsuitability for information that requires the audience to take some time to understand, and their large file size.

According to [8] on the 6 principles of understanding that demonstrate deep and accurate understanding, it can be summarized that it is an ability; to explain principles, concepts, theories, events, phenomena, information and facts, to interpret and translate the meanings of stories, to apply or use in situations that are different from what was learned, to have perspectives in various dimensions, to know the stories and things around oneself, and to have a complete understanding and knowledge of oneself. This is also in accordance with a study of [9] which focused on the influence of infographics in communication of complex information. In the project "Roo Soo Flood!" video-formatted infographics in the form of an animation series were used.

After publishing the animation series, it was found that it was easier, faster, and clearer for the general public to learn how to respond to flooding than only the use of textual information. Most people were found have a positive response with satisfaction at the highest level. Furthermore, in the work of [10], the study of form perception revealed the mechanism of emotional response associated with the semantic capacity of the design object and special features of its visual organization. Perception model of visual images in design was suggested, including recognition, comparison and dialogue processes. The findings are scientifically-based recommendations, tailored to visual perception and aimed at creating emotional comfort in design.

Furthermore, it was found that Ramkhamhaeng University's graduates participating in the 2019 royal graduation were satisfied overall with the information on the ceremony received via the Android OS application at a high level $\overline{\mathrm{x}}=4.44$ ) as shown in Table 1 .

This might be because the infographics were presented via RUGrad Version 1.0, an Android OS application, that could be downloaded quickly and conveniently through Google Play Store using processing devices such as computers, mobile phones, and tablets. This complies with [11] which concluded that Android is an open source operating system by Google Inc. that has gained a high level of popularity due to the large number of devices of different levels and varieties running Android OS. Its compatibility with devices with different screen resolutions and sizes allows users to use it with their preferred devices. As for the graduates' use of the infographics, they found the infographics useful to their participation in the 2019 royal graduation ceremony.

This might be due to text and graphic presentation used for content that conveyed clear meanings, as well as the use of appropriate audio narration, speaking rhythm, animations, and sound effects that can be easily viewed through portable electronic devices and can be viewed many times as required. This is in accordance with [12] stating that graphic design is an art that uses visual elements, text, and colours to deliver a message. It is also entwined with communication, interpretation, and attractiveness. 
Table 1. Mean and Standard Deviation of Ramkhamhaeng University graduates' understanding of the royal graduation ceremony and satisfaction towards infographics on the Android OS application.

\begin{tabular}{|c|c|c|c|}
\hline Assessment list & $\overline{\mathbf{x}}$ & SD & Interpretation \\
\hline Understanding the commencement ceremony & 4.49 & .46 & High \\
\hline 1. Graduation Registration & 4.40 & .60 & High \\
\hline $\begin{array}{l}\text { 2. Graduates attendance report and royal } \\
\text { graduation ceremony practices }\end{array}$ & 4.44 & .58 & High \\
\hline $\begin{array}{l}\text { 3. Official rehearsals at Kong Krailat Building } \\
\text { (KLB) and King Ramkhamhaeng the Great } \\
\text { Auditorium }\end{array}$ & 4.47 & .56 & High \\
\hline 4. Royal graduation ceremony day & 4.54 & .56 & Very high \\
\hline $\begin{array}{l}\text { 5. Graduates' attire according to the university } \\
\text { announcement on graduates' dress code for the } \\
\text { royal graduation ceremony }\end{array}$ & 4.58 & .56 & Very high \\
\hline $\begin{array}{l}\text { 6. Practices for monks participating in the royal } \\
\text { graduation ceremony }\end{array}$ & 4.49 & .57 & High \\
\hline 7. Prohibition for graduates & 4.54 & .56 & Very high \\
\hline 8. Diagram for the graduation ceremony process & 4.53 & .56 & Very high \\
\hline 9. How to use the application & 4.43 & .64 & High \\
\hline $\begin{array}{l}\text { Satisfaction with infographics through applications } \\
\text { Android operating system }\end{array}$ & 4.44 & .50 & High \\
\hline $\begin{array}{l}\text { 1. The infographics' design is interesting for } \\
\text { watching until the end }\end{array}$ & 4.38 & .62 & High \\
\hline 2. The infographics are unique, recognizable. & 4.38 & .63 & High \\
\hline $\begin{array}{l}\text { 3. Font color/symbol color/background color used } \\
\text { is suitable }\end{array}$ & 4.42 & .63 & High \\
\hline $\begin{array}{l}\text { 4. The placement of the characters is appropriate } \\
\text { and easy to understand. }\end{array}$ & 4.46 & .57 & High \\
\hline 5. The graphics used can convey meaning clearly. & 4.49 & .61 & High \\
\hline 6. Animations and sound effects are appropriate. & 4.41 & .61 & High \\
\hline $\begin{array}{l}\text { 7. The narration and the timing of the speech are } \\
\text { appropriate. }\end{array}$ & 4.49 & .56 & High \\
\hline $\begin{array}{l}\text { 8. The infographics are useful for Ramkhamhaeng } \\
\text { University's royal graduation ceremony. }\end{array}$ & 4.50 & .57 & Very high \\
\hline
\end{tabular}

The findings of [13] concluded that we can understand the semantic effect of movement as applied to digital typography, how to manipulate it to fulfill an objective and use motion graphics and animation to communicate a message with better efficiency than with another medium. Meanwhile $[14,15]$ stated that advantages of infographics can be summarized as follows:

(1) They are interesting and attractive and do not require a lot of time to keep the audience's attention.

(2) They help reduce the issues of too much or unnecessary information.

(3) They are easy to watch and understand.

(4) They help increase memorizing efficiency with the use of graphics.

(5) They can be easily accessible to large groups of people, transcending through the limitations of age, ethnicity, and language.

People also favour sharing infographics to their peers via social networks. This is in line with a study of $[16,17]$ on the development of infographic media for an introduction to network course for 3rd year vocational students which found that learners' satisfaction towards the infographics was at the highest level [18].

\section{Conclusion}


The conclusion of the study "Designing of Infographic via Android Operating System Application for Royal Graduation Ceremony of Ramkhamhaeng University" is as follows;

1. The infographics for the Royal graduation ceremony of Ramkhamhaeng University were offered on the application RUGrad Version 1.0 on Android OS which could be downloaded via Google Play Store and included these following items on its menu (1.1) Procedures for the graduation ceremony, (1.2) Graduation registration, (1.3) Attendance report, (1.4) Rehearsals, (1.5) Royal graduation ceremony day, (1.6) Graduates' attires, (1.7) Practices for monks, (1.8) Prohibitions for graduates, (1.9) Diagram for the graduation ceremony process, and (1.10) How to use the application..

2. The quality of infographics shown via the Android OS application was found to be suitable in all areas with the overall value of 0.90 . As for quality assessment scores by aspect, text and symbols were given 0.85, Animation 0.93, Sound 0.85, and Content 1.00.

3. Graduates of Ramkhamhaeng University participating the 2019 Royal graduation ceremony were found with an overall high level of understanding on the ceremony information presented with infographics via the Android OS application $(\overline{\mathrm{x}}=4.49)$. They were also found with an overall high level of satisfaction towards the infographics for the Royal graduation ceremony presented via the Android OS application $(\overline{\mathrm{x}}=4.44)$.

\section{Acknowledgement}

The researcher team would like to thank the president of Ramkhamhaeng University Assoc. Prof. Wuttisak Larbchareonsub and the grant from the Research and Development Institute Ramkhamhaeng University, as well as all advisors and experts who have kindly provided feedback and inspected the quality of the instruments used in this research and development project which contributed greatly to its successful completion.

\section{References}

1. J. Sakurada, N. Hiranyapruek, Basic Infographics. (Nonthaburi, Premier, 2015)

2. D. Huang et al., Remote Sensing of Environment 106, 106-122 (2007)

3. D. Ushakov et al., Public Policy and Administration 18(4), 395-404 (2019)

4. 37 Years of Ramkhamhaeng University (Bangkok, Press Office of Ramkhamhaeng University, 2008)

5. T. Namwong, Veridian E-Journal 4(4), 14-24 (2017)

6. T. Nanchanok, Infographic Design (Bangkok, Witty Group Publishing House, 2016)

7. C. Phusumat, Principle Infographic (Nonthaburi, IDC Premier, 2017)

8. G. Wiggins et al., Understanding by Design (Association for Supervision and Curriculum Development, Virginia, 2005)

9. N. Tinwirat, The influence of infographics on complex information: a case study of "Roo Soo Flood". Master of Arts Thesis (Bangkok, Silpakorn University, 2012)

10. M. Kornienko et al., Procedia: Social and Behavioral Sciences 206(17), 365-368 (2015)

11. S. Thongdi, Get to know Android (2012) http://www.sourcecode.in.th/ articles.php?id=71

12. T. Harmer, What is graphic design? https:/www.lynda.com/InDesign-tutorials / Whatgraphic-design /633854/711156-4.html

13. J.A. Brandao et al., Procedia Manufacturing 3, 6376-6379 (2015) 
14. D. Ushakov, Montenegrin Journal of Economics 13(1), 171-179 (2017)

15. P. Rasi, The development of infographic media in an introduction to computer network course for the third year vocational students (Educational Thesis - Master's degree, Rajamangala University of Technology Thanyaburi, 2016)

16. A. Rattanatranurak et al., The EUrASEANs: Journal on Global Socio-Economic Dynamics 1(20), 23-29 (2020)

17. D. Ushakov et al., Journal of Environmental Management and Tourism 11(6), 13161327 (2020).

18. V. Vongprasert, The EUrASEANs: Journal on Global Socio-Economic Dynamics 2(9), 23-32 (2018) 